\title{
RESRO: A spatio-temporal model to optimise regional energy systems emphasising renewable energies
}

\author{
S. Hausl ${ }^{1,2}$ a, M. Biberacher ${ }^{1}$ and S. Gadocha ${ }^{1}$ \\ ${ }^{1}$ Research Studios Austria Forschungsgesellschaft mbH - Studio iSPACE, Salzburg, Austria \\ ${ }^{2}$ Technische Universität München, Munich, Germany
}

\begin{abstract}
RESRO (Reference Energy System Regional Optimization) optimises the simultaneous fulfilment of the heat and power demand in regional energy systems. It is a mixed-integer program realised in the modelling language GAMS. The model handles information on geographically disaggregated data describing heat demand and renewable energy potentials (e.g. biomass, solar energy, ambient heat). Power demand is handled spatially aggregated in an hourly time resolution within 8 type days. The major idea is to use a high-spatial, low-temporal heat resolution and a low-spatial, hightemporal power resolution with both demand levels linked with each other. Due to high transport losses the possibilities for heat transport over long distances are unsatisfying. Thus, the spatial, raster-based approach is used to identify and utilise renewable energy resources for heat generation close to the customers as well as to optimize district heating grids and related energy flows fed by heating plants or combined heat and power (CHP) plants fuelled by renewables. By combining the heat and electricity sector within the model, it is possible to evaluate relationships between these energy fields such as the use of CHP or heat pump technologies and also to examine relationships between technologies such as solar thermal and photovoltaic facilities, which are in competition for available, suitable roof or ground areas.
\end{abstract}

\section{Introduction}

A significant part of European energy consumption is needed for the heat and electricity demand. Heat and electricity production are still dominated by fossil fuels and nuclear power. There are various challenges like climate change, concerns about the use of nuclear power and the current import dependency on fossil fuels and nuclear substances. Therefore, improvements in energy enduse efficiency, energy production efficiency (e.g. co-generation) and the enhanced use of regionally available renewable energy sources are necessary to be considered in policy and planning issues.

The energy system model RESRO provides support for decision and policy makers to build strategies towards a more sustainable energy supply system. The use of scenario analysis allows the derivation of an optimised energy setup and the testing for key sensitivities in the energy system of interest. These outcomes reveal important conclusions for policy actions and provide strategic information to stakeholders.

A former version of RESRO and the according model framework around RESRO has been presented in Biberacher/Gadocha [1] and used in projects like RECO2NWK [2] and BioSpaceOpt, [3]. The latest version is currently used in the project CLEOS [4].

\footnotetext{
a e-mail : stephan.hausl@researchstudio.at
} 


\section{Model basics}

RESRO (Reference Energy System Regional Optimization) optimises the simultaneous fulfilment of the heat and power demand in regional energy systems, emphasising renewable energies with respect to spatial aspects. The model handles information on geographically disaggregated data describing heat demand and renewable energy potentials (e.g. biomass, solar energy, ambient heat) on a raster basis. Power demand is modeled spatially aggregated and in an hourly time resolution within 8 type days. The major idea is to use a high-spatial, low-temporal resolution for heat demand and a lowspatial, high-temporal resolution for power demand. Heat and power supply are linked within the model even though they are operated on different spatial and temporal resolutions. To transform the costs and generated energy of a type-day on the coarser seasonal time resolution or on one year, a type-day matrix is used which includes the amount of appearances of a certain type-day within one year.

Due to high transport losses the possibilities for heat transport over long distances are unsatisfying. Thus, the spatial, raster-based approach is used to identify and utilise renewable energy resources for heat generation close to the customers as well as to optimize district heating (dh) grids and related energy flows fed by heating plants or combined heat and power (CHP) plants fuelled by renewables such as biomass. By combining the heat and electricity sector within the model, it is possible to evaluate relationships between these energy fields such as the use of CHP or heat pump technologies and also to examine relationships between technologies such as solar thermal and photovoltaic facilities, which are in competition for available, suitable roof or ground areas.

RESRO is implemented as a mixed-integer programming model realised in the modelling language GAMS. It is a snap-shot model which optimises the expansion and operation of an energy system within one year, so all data (including costs) are annualised. The objective function of the model is defined as highest economic efficiency with respect to all constraints given in the region.

\section{Input data}

Input data can be processed and derived and results can be shown in ArcGIS. To take into account the spatial relevance of the single elements of the energy system in an appropriate way, all relevant spatial data are disaggregated to a consistent spatial resolution. This includes the energy potentials as well as the heat demand structure. The region of interest is segmented into single raster cells (subregions), which represent the smallest spatial unit in the model. The smallest size of raster cells accomplished so far is $100 \mathrm{~m} \times 100 \mathrm{~m}$.

The spatial dimension of input information such as heat demand or potentials of RES creates the need for spatial analysis before running RESRO. In general, the heat sector is depicted on a highly detailed spatial raster and a low detailed time resolution with four different seasons a year. The electricity sector on the other hand is included without a spatial component because the examined regions are mostly of small scales and we assume no severe restrictions and losses for electricity transport. Nevertheless, the power sector of RESRO uses a detailed hourly time component which is modelled within eight type days (four seasons \& working/non-working days). Figure 1 shows an excerpt of heat and power demand structure. 


\section{$2^{\text {nd }}$ European Energy Conference}
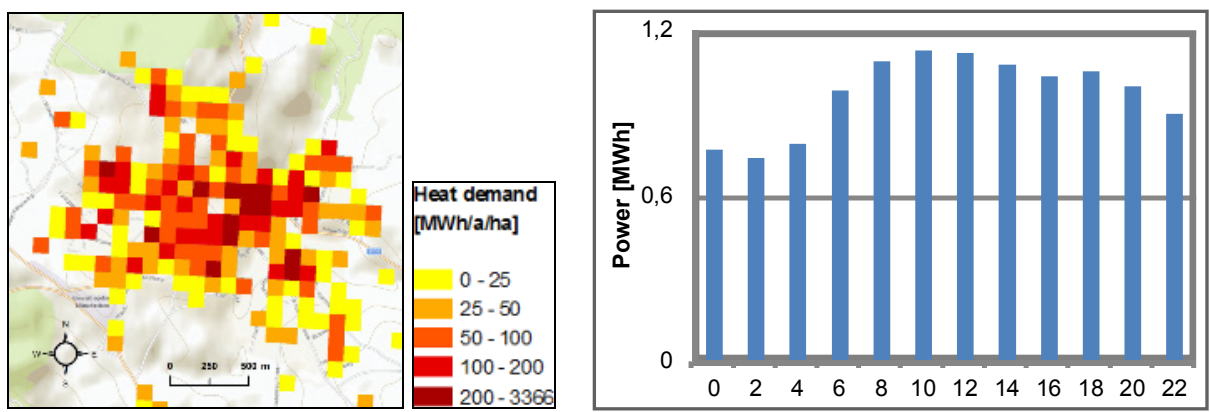

Figure 1 Raster-based heat demand (left fig.) and power demand on a type-day (spring-weekday) with 2-hour resolution (right fig.)

However, there are exclusions and special rules regarding time-space resolution for some parts due to linkage between heat and power sector. Figure 2 shows the input data for demand and potentials and their temporal and spatial utilization in RESRO.

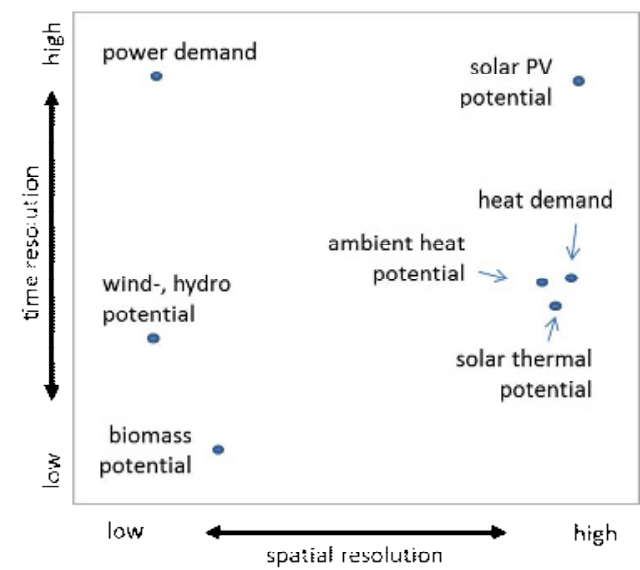

Figure 2 Space and time resolution of input data (energy demand and RES potentials) in RESRO

\section{Space resolution}

high Raster cells, up to $100 \mathrm{~m} \times 100 \mathrm{~m}$

low aggregated on region of interest, no spatial component

\section{Time resolution}

high Hourly resolution ${ }^{\mathrm{b}}$ within 8 type days:

4 seasons a year, 2 days (working / non-working) in each season

low 4 seasons

Solar thermal and ambient heat potentials are derived and utilised in the same resolution as the heat demand, while PV potentials have an additional detailed time resolution, represented by according global irradiation values on an hourly basis, to suit the electric power demand resolution. PV potentials however are depicted spatially detailed in order to compete for available solar areas with solar thermal panels. Biomass potentials are aggregated because it is possible to transport biomass within a small region, so there is only a restriction regarding the amount of biomass used

\footnotetext{
${ }^{\mathrm{b}}$ to enhance the performance hourly values can be aggregated in 2-hour or 4-hour blocks.
} 


\section{EPJ Web of Conferences}

throughout a year. Wind and water power potentials are regarded exogenously, depending on the examined region.

Input data that don't have any spatio-temporal dimension such as specific costs for technologies and also constraint values for certain barriers such as greenhouse gas upper boundaries which count for the entire region and time horizon of interest are also considered in the model.

\section{Optimisation}

Core of the model is the optimisation part in which the energy system is defined by constraint equations and an objective function. The model is implemented as a mixed-integer (MIP) model with semi-continuous ${ }^{\mathrm{c}}$ variables. In the following section we present the model equations with all variables and parameters. Due to the different time resolutions, we distinguish between time-detailed and non-time-detailed supply technologies and therefore need different equations for the two of them. Table 1 and 2 name all occurring indices, variables and parameters ${ }^{\mathrm{d}}$.

Table 1 Model Indices

\begin{tabular}{|c|c|}
\hline Indices & \\
\hline $\begin{array}{l}\text { Amb } \\
\text { Biom } \\
\text { d } \\
\text { g } \\
\text { hr } \\
\text { nb } \\
\text { nb-reg } \\
\text { p } \\
\text { p_chp } \\
\text { p_h } \\
\text { PV } \\
\text { reg } \\
\text { reg-nb } \\
\text { s } \\
\text { s_chp } \\
\text { s_el } \\
\text { s_g } \\
\text { s_th } \\
\text { sn } \\
\text { Sol } \\
\text { ST } \\
\text { t } \\
\text { t_Biom } \\
\text { t_el } \\
\text { t_h }\end{array}$ & $\begin{array}{l}\text { subset of s, ambient heat technologies } \\
\text { biomass } \\
\text { day } \\
\text { grid technology (e.g. district heating) } \\
\text { hour } \\
\text { subset of reg,neighbour region } \\
\text { from nb to reg } \\
\text { plants, centralised } \\
\text { subset of } p \text {, chp } \\
\text { subset of } p \text {, only-heat } \\
\text { subset of } s \text {, photovoltaic } \\
\text { subregions (raster cells) } \\
\text { from reg to nb } \\
\text { supply technology, decentralised } \\
\text { subset of } s \text {, only chp } \\
\text { subset of } s \text {, only electric or chp } \\
\text { subset of } s \text {, grid-bound heat exchanger } \\
\text { subset of } s \text {, only heat } \\
\text { season } \\
\text { subset of s, Solar technologies, ST+PV } \\
\text { subset of } s \text {, solar thermal heat } \\
\text { technology, supply+plants } \\
\text { subset of } t \text {, biomass technologies } \\
\text { subset of t, electric or chp } \\
\text { subset of t, only-heat }\end{array}$ \\
\hline
\end{tabular}

\footnotetext{
${ }^{\mathrm{c}}$ These variables can only be zero or above a certain limit.

${ }^{\mathrm{d}}$ Units can differ in certain cases.
} 


\section{$2^{\text {nd }}$ European Energy Conference}

Table 2 Variables and parameters

\begin{tabular}{|c|c|c|c|c|}
\hline \multicolumn{2}{|c|}{ Variables and parameters } & \multirow{2}{*}{$\frac{\text { Unit }}{\mathrm{kWh}}$} & \multirow{2}{*}{$\frac{\text { Variable }}{\mathrm{x}}$} & \multirow[t]{2}{*}{ Parameter } \\
\hline Add & Additional power demand & & & \\
\hline Amax & Maximum available solar areas & $m^{2}$ & & $\mathrm{x}$ \\
\hline Irr & Irradiation values & $\mathrm{kWh} / \mathrm{m}^{2}$ & & $x$ \\
\hline $\mathrm{Cp}$ & Installed capacity & kW & $x$ & \\
\hline Cp_n & New Capacity & $\mathrm{kW}$ & $x$ & \\
\hline Dem_el & Power demand & kWh & & $x$ \\
\hline Dem_h & Heat demand & kWh & & $x$ \\
\hline E & Energy input, Primary energy level & kWh & $x$ & \\
\hline Ex & Export revenues for power & $€ / \mathrm{kWh}$ & & $\mathrm{x}$ \\
\hline FLH & Typical full load hours & h & & $x$ \\
\hline Fw & Heat flow between subregions & kWh & $x$ & \\
\hline G_n & New grid capacity & kWh & $x$ & \\
\hline $\mathrm{hr}$ & number of hour(-blocks) per type-day & & & $x$ \\
\hline 1 & Installation costs, capacity-dependant & $€ / \mathrm{kW}$ & & $x$ \\
\hline Im & Import costs for power & $€ / \mathrm{kWh}$ & & $\mathrm{x}$ \\
\hline Ld & Heat load & kWh & $x$ & \\
\hline Ld_ex & Load, Power export & kWh & $x$ & \\
\hline Ld_im & Load, Power import & kWh & $x$ & \\
\hline Lk & Linkage capacity of dh grid & kWh & $x$ & \\
\hline$M$ & Maintenance costs, capacity-dependant & $€ / \mathrm{kW}$ & & $x$ \\
\hline Op & Operation costs, load-dependant (fuel) & $€ / \mathrm{kWh}$ & & $\mathrm{x}$ \\
\hline Pot & Potential & kWh & & $x$ \\
\hline TDM & Type-day Matrix & & & $x$ \\
\hline $\mathrm{v}$ & Heat transportation losses between subregions & & & $x$ \\
\hline$\eta \_$el & Electric efficiency & & & $x$ \\
\hline$\eta$ th & Heat efficiency & & & $x$ \\
\hline
\end{tabular}

The objective function of the model represents the overall system costs $\mathbf{Z}$, which are minimised:

$$
\begin{aligned}
\mathrm{Z} & =\sum_{\mathrm{t} \_\mathrm{h}, \mathrm{sn}, \mathrm{reg}}\left(E_{t \_h, s n, r e g} * \mathrm{Op}_{\mathrm{t} \_\mathrm{h}}\right)+\sum_{\mathrm{t} \_\mathrm{el}, \mathrm{sn}, \mathrm{d}, \mathrm{hr}, \mathrm{reg}}\left(E_{t \_e l, s n, d, h r, r e g} * \mathrm{Op}_{\mathrm{t} \_\mathrm{el}} * \mathrm{TDM}_{\mathrm{sn}, \mathrm{d}}\right) \\
& +\sum_{\mathrm{t}, \mathrm{reg}}\left(C p \_n_{t, r e g} *\left(\mathrm{I}_{\mathrm{t}}+\mathrm{M}_{\mathrm{t}}\right)\right)+\sum_{\mathrm{g}, \mathrm{reg}} \mathrm{G} \_\mathrm{n} * \mathrm{I}_{\mathrm{g}} \\
& +\sum_{\mathrm{sn}, \mathrm{d}, \mathrm{hr}}\left(L d_{-} i m_{s n, d, h r} * \mathrm{Im}_{\mathrm{sn}, \mathrm{d}, \mathrm{hr}}-L d \_e x_{s n, d, h r} * \mathrm{Ex}_{\mathrm{sn}, \mathrm{d}, \mathrm{hr} r}\right) * \mathrm{TDM}_{\mathrm{sn}, \mathrm{d}}
\end{aligned}
$$

The demand fulfilment equations for both heat and power demand are essential.

The following equation shows the heat demand fulfilment equation, valid for all seasons and regions:

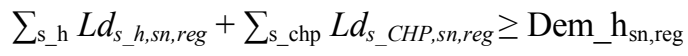

with seasonal heat output Ld from decentralised technologies $\mathrm{s}_{-} \mathrm{h}$ and $\mathrm{s} \_$chp calculated by:

$$
\begin{gathered}
L d_{s_{-} h, s n, r e g}=E_{s_{-} h, s n, r e g} * \eta \mathrm{th}_{\mathrm{s}_{-} \mathrm{h}} \\
L d_{s_{-} C H P, \text { sn }, \text { reg }}=\sum_{\mathrm{d}, \mathrm{hr}}\left(E_{s_{-} c h p, s n, d, h r, r e g} * \eta \eta_{-} \mathrm{h}_{\mathrm{s}_{-} \mathrm{chp}} * \mathrm{TDM}_{\mathrm{sn}, \mathrm{d}}\right)
\end{gathered}
$$

The following equation illustrates the power demand fulfilment which counts for every hour(block) during the type-days. All technologies with power output, power sales, -imports and additional power demand besides the original power demand are included.

$$
\sum_{\mathrm{t} \_\mathrm{el}, \mathrm{reg}}\left(E_{t \_e l, s n, d, h r, r e g} * \eta \eta_{-} \mathrm{e}_{\mathrm{t} \_\mathrm{el}}\right)+L d \_i m_{s n, d, h r}-L d \_e x_{s n, d, h r}=\mathrm{Dem}_{-} \mathrm{el} \mathrm{l}_{\mathrm{sn}, \mathrm{d}, \mathrm{hr}}+A d d_{s n, d, h r}
$$

with additional power demand from heat supply technologies like heat pumps, which is disaggregated uniformly from the seasonal heat demand resolution to the hourly type-day time resolution of the power demand: 


$$
A d d_{s n, d, h r}=\sum_{\mathrm{s}_{-} \mathrm{h}, \mathrm{reg}} L d_{s_{-}, \text {sn, reg }} /\left(\mathrm{d}_{\mathrm{sn}} * \mathrm{hr}\right)
$$

Of course power output from the facilities must not exceed the installed capacity. Every technology has its certain characteristics regarding operation. This is represented by typical full load hours for each technology in the following equations and prevents for example single heating boilers from being operated throughout the entire year. The following two equations model this issue for onlyheat technologies $t \_h$ throughout the entire year (7) and within the seasons (8):

$$
\begin{gathered}
\sum_{\mathrm{sn}}\left(E_{t_{-} h, s n, r e g} * \eta \mathrm{th}_{\mathrm{t}_{-} \mathrm{h}}\right) \leq \mathrm{Cp}_{t_{-} h, \text { reg }} * \mathrm{FLH}_{\mathrm{t}_{-} \mathrm{h}} \\
E_{t_{-} h, s n, \text { reg }} * \eta \eta_{-} \mathrm{th}_{\mathrm{t}_{-} \mathrm{h}} \leq \mathrm{Cp}_{t_{-} h, \text { reg }} * \mathrm{~d}_{\mathrm{sn}} 24
\end{gathered}
$$

For technologies generating not only heat, we use the temporal resolution of the type-days. While equation (9) restricts the energy output per installed capacity within one year, equation (10) does the same on the small scale of one hour(-block):

$$
\begin{aligned}
& \sum_{\text {sn,d,hr }}\left(E_{t \_e l, s n, d, h r, r e g} * \eta_{\_} \mathrm{el}_{\mathrm{t} \_\mathrm{el}} * \mathrm{TDM}_{\mathrm{sn}, \mathrm{d}}\right) \leq \mathrm{Cp}_{t \_e l, r e g} * \mathrm{FLH}_{\mathrm{t} \_ \text {el }} \\
& E_{t \_l l, s n, d, h r, r e g} * \eta \_\mathrm{l}_{\mathrm{t} \_\mathrm{el}} \leq \mathrm{Cp}_{t \_ \text {el,reg }}(24 / \mathrm{hr})
\end{aligned}
$$

Energy generation from RES is restricted with respect to their potentials. Since generated energy from solar technologies depends on irradition values, we apply these values additionally as a multiplier. Capacity variables of solar technologies represent the area of installed solar panels. For solar thermal heat technologies this is carried out seasonally, while for the photovoltaic facilities we use hourly values for each season:

$$
\begin{gathered}
E_{S T, \text { sn,reg }} \leq C p_{S T, \text { reg }} * \operatorname{Irr}_{\mathrm{ST}, \mathrm{sn}} \\
E_{P V, s n, \text {, hr, reg }} \leq C p_{P V, \text { reg }} * \operatorname{Irr}_{\mathrm{PV}, \mathrm{sn}, \mathrm{hr}}
\end{gathered}
$$

For certain technologies there are raster-dependent barriers, concerning the maximum installed capacity. This is valid for solar technologies like solar thermal and PV whose installed areas must not exceed available roof or ground areas and for ambient heat technologies whose potentials are limited within each subregion.

$$
\begin{gathered}
\sum_{\mathrm{sol}} C p_{\text {Sol,reg }} \leq \mathrm{Amax}_{\mathrm{reg}} \\
\sum_{\mathrm{Amb}, \mathrm{sn}} E_{A m b, s n, \text { reg }} \leq \operatorname{Pot}_{\mathrm{Amb}, \mathrm{reg}}
\end{gathered}
$$

Since biomass transport is possible and performed within small regions, we apply the regional biomass potential on the biomass consumption of the entire region of interest:

$$
\sum_{\mathrm{t} \_ \text {Biomsn,reg }} E_{t_{-} \text {Biom,sn,reg }}+\sum_{\mathrm{t} \_ \text {Biom,sn,d,hr,reg }}\left(E_{t_{-} \text {Biom,sn, }, \text {,hr,reg }} * \mathrm{TDM}_{\mathrm{sn}, \mathrm{d}}\right) \leq \sum_{\text {reg }} \operatorname{Pot}_{\text {Biom,reg }}
$$

We use several equations to model the expansion and operation of the district heating (dh) grid, fed by centralised facilities like heating or CHP plants. The first equation mentioned here expresses that the capacity of the district heating $(\mathrm{dh})$ grid in every subregion must be higher or equal than the capacities of the installed centralised heat facilities in this subregion and the (dh) linkage capacities from endogenous neighbouring subregions (minus transportation losses):

$$
\sum_{\mathrm{p}}\left(C p_{p, \text { reg }} * \mathrm{FLH}\right)+\sum_{\mathrm{nb}}\left(L k_{n-\text {-reg }} *(1-\mathrm{v})\right) \leq C p_{\text {g,reg }}
$$

Equation (17) restricts the yearly heat flow between neighbouring subregions by using the installed linkage capacity as upper barrier:

$$
\sum_{\mathrm{sn}} F w_{n b-r e g, s n} \leq L k_{n b-r e g}
$$




\section{$2^{\text {nd }}$ European Energy Conference}

Equation (18) is used to balance the heat flow for one subregion and for each of the seasons. Basically, export and consumption of heat within a subregions' district heating grid must equal import and generation. Decentralised grid-bound heat-exchangers act as supply technologies consuming heat from the grid, while centralised heat or CHP plants work as (dh) generation facilities:

$$
\begin{aligned}
\sum_{\mathrm{nb}} F w_{r e g-n b, s n}+E_{s \_g, s n, r e g} & =\sum_{\mathrm{nb}}\left(F w_{n b-r e g, s n} *(1-\mathrm{v})\right)+\sum_{\mathrm{p}_{-} \mathrm{h}}\left(\mathrm{E}_{\mathrm{p}_{-} \mathrm{h}, \mathrm{sn}, \mathrm{reg}} * \eta_{-} \mathrm{th} \mathrm{p}_{\mathrm{p}_{-} \mathrm{h}}\right) \\
& +\sum_{\mathrm{p}_{-} \text {chp }, \mathrm{d}, \mathrm{hr}}\left(E_{p_{-} c h p, s n, d, h r, r e g} * \eta_{-} \mathrm{th} \mathrm{p}_{\mathrm{p}_{-} \text {chp }} * \mathrm{TDM}_{\mathrm{sn}, \mathrm{d}}\right)
\end{aligned}
$$

There are more equations, which are mostly necessary to ease scenario analysis with RESRO and restrict certain variables or outcomes. They shall just be mentioned and explained here briefly:

- Usage of technologies: possibility to restrict the share of certain technologies in the supply mix

- Import of grid power: possibility to restrict the share of grid power in the power supply

- Greenhouse gas (GHG) emissions: possibility to restrict GHG-emissions

\section{Results}

Scenario analysis with RESRO provides results which support decision making regarding energy strategies. Results such as overall system costs, GHG-emissions, share of renewables or share of grid power import are important outcomes to judge an energy strategy. Spatial results can be shown in ArcGIS while aggregated results can be released e.g. in Excel.

The following figures $3-5$ show results for two exemplary scenarios for a small excerpt of a region of interest. They differ in the usage of centralised heat supply (left figures: with district heating and CHP, right figures: without district heating and CHP). The usage of dh and chp (left figures) leads to a different supply system than the scenario without dh and chp: limited, regionally available biomass ressources are used in centralised chp plants which supply heat to the dh grid and produce power at the same time. PV installations are less than in the right scenario while heat supply from oil is much higher than in the scenario without dh and chp. This is caused by the differing allocation of the biomass ressources on centralised chp plants in one case and on decentralised pellet heating systems in the other case, which leads to a higher heat output from biomass in the right hand side scenario and therefore causes the differing oil share between the scenarios.
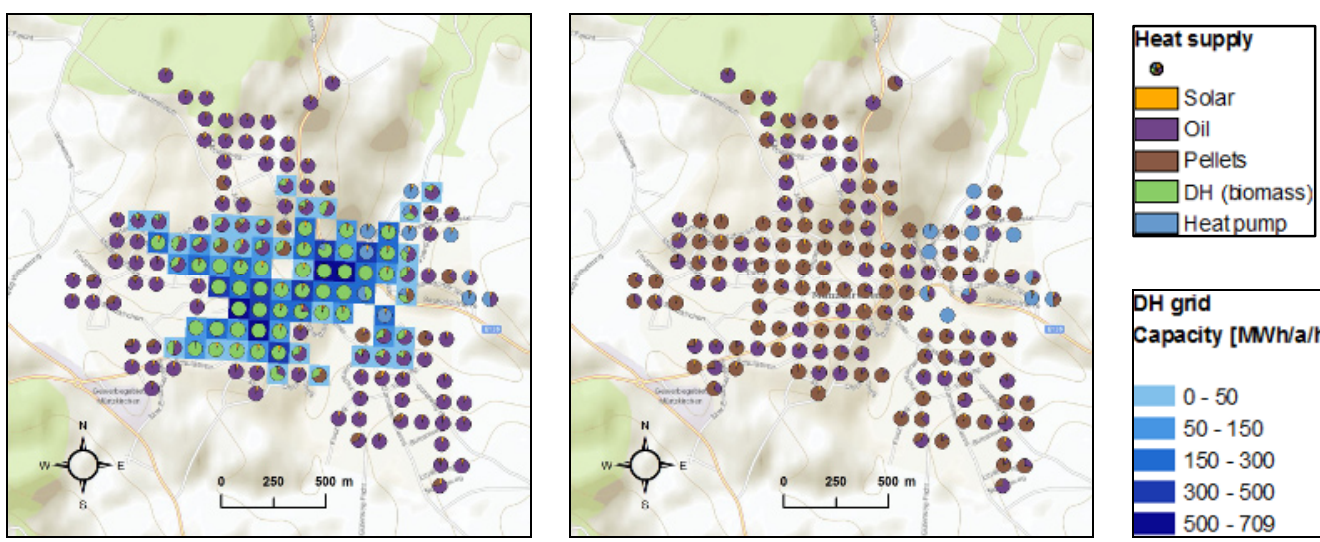

Figure 3 Raster-based annual heat supply

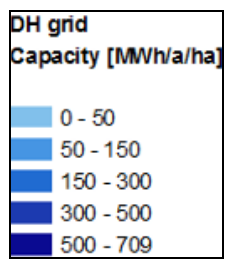



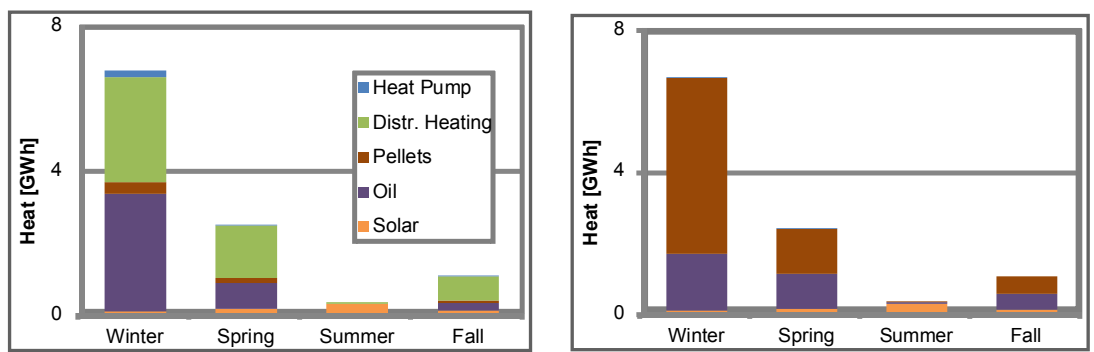

Figure 4 Seasonal heat supply
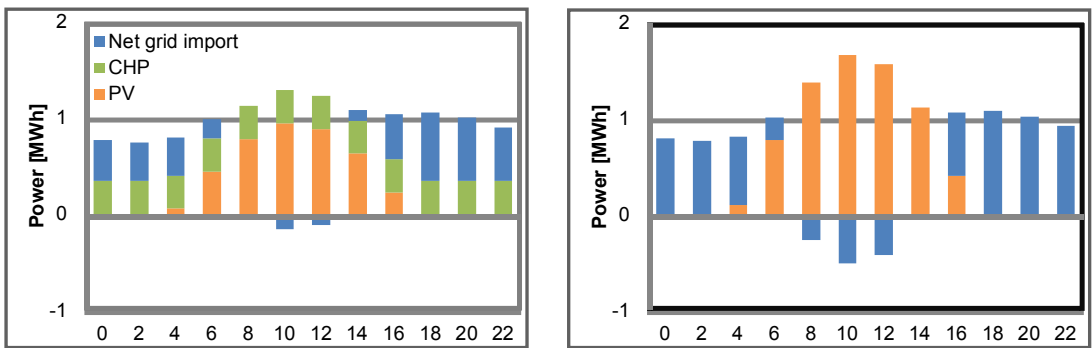

Figure 5 Power supply on a type-day (spring-weekday)

\section{References}

[1] M.Biberacher, S. Gadocha, GIS based model to optimize the utilization of renewable energy carriers and related energy flows, $18^{\text {th }}$ World IMACS / MODSIM Congress, Cairns, Australia (2009)

[2] M. Biberacher et. al, RECO2NWK - Regional concepts of CO2-neutral heat demand and refrigeration load covering (2010)

[3] M. Biberacher et. al, BioSpaceOpt - Regional integrative assessment of bioenergy utilisation paths (2011)

[4] S. Hausl et. al, CLEOS - Climate sensitivities of regional energy systems, in progress (2012) 